\title{
STUDY OF THE TOLERANCE AND ATTITUDE OF THE SOCIETY TOWARDS INTERNATIONAL STUDENTS OF VARIOUS CULTURAL BACKGROUNDS IN BULGARIA
}

\author{
N. Musurlieva ${ }^{1 *}$, M. Stoykova \\ Department of Social Medicine and Public Health, Faculty of Public Health, \\ Medical University - Plovdiv, Bulgaria
}

\begin{abstract}
The tolerance of a society towards people with different cultural, language, religious and social background is an indicative feature of the social and cultural competence level of the society itself. Aim: To research the tolerance and attitude of the society towards international students of various cultural backgrounds.

Materials and methodology: A direct individual survey among 43 international students in general and dental medicine at the Medical University of Plovdiv was performed. A specially prepared questionnaire, including questions, targeted at examining the knowledge of the foreign students of the Bulgarian traditions and culture, the Bulgarian language and their opinion if their religious believes, cultural identification etc. are respected was used. The results are processed by SPSS v. 14 . A parametric test was used.

Results: Most of the respondents $-54 \%$ share that they have being in Bulgaria for more than three years. The main reasons for their stay at the country are their studies. Three of the interviewed individuals state war as a main reason for their arrival. $67 \%$ of the students feel "welcomed" and only eight share the opinion that they are "unwanted" foreigners. $70 \%$ of the interviewed know and speak Bulgarian language. Almost the same percentage are acquainted with the Bulgarian culture and customs. More than half of the interviewed $(81 \%)$ feel that their cultural identity and religious believes are respected by their fellow students and teachers at the university.

Conclusion: The results show that the academic and students community and the society, in general, are tolerant and respectful towards the cultural identity of the foreign students.
\end{abstract}

Key words: tolerance, foreign students, cultural community

\section{INTRODUCTION}

The tolerance of a society towards people with different cultural, language, religious and social background is an indicative feature of the social and cultural competence level of the society itself. The tolerance is a desired feature of the human behaviour, which is taught and acquired in the early childhood through the adoption of appropriate methods (Chlewinski). The intolerance is an aggregation of prejudices, negative attitudes, based on false information. Frequently, it is illogical, but persistent in time (Hammer) $(1,2,3)$. There

\footnotetext{
*Correspondence to: Nina Musurlieva, $D D, P h D$; Medical University - Plovdiv, Faculty of Public Health, Department of Social Medicine, and Public Health; MU-Plovdiv, Vasil Aprilov 15a; Plovdiv, Bulgaria, e-mail: nina_mussurlieva@abv.bg
}

are about 70,000 ethnic and national groups around the world. The social tension between them is created by the ethnic intolerance and various prejudices of the society $(3,4)$. The presence of attitudes and prejudices are forming the base of social relations which help or hinder the communication with other people, considered as close or different, pleasant or unpleasant. In the relatively newly formed countries (Bosnia and Herzegovina, Kosovo etc.) marginalization of the various ethnic groups is observed (Albanians, Serbians etc.). The ethnic model of tolerance and mutual respect exists for centuries in Bulgaria and this model must be preserved for the future as well.

\section{AIM}

To research of the tolerance and attitude of the society towards international students of various cultural backgrounds in Bulgaria. 


\section{HYPOTHESIS OF THE RESEARCH}

The foreign students feel tolerance and respect of their cultural identity by the fellow students and teachers at Medical University - Plovdiv and the society.

\section{MATERIALS AND METHODOLOGY}

In order to achieve the purpose, a direct individual survey among 43 international students in general and dental medicine at the Medical University of Plovdiv was performed. A specially prepared questionnaire, including questions, targeted at examining the knowledge of the foreign students of the Bulgarian traditions and culture, the Bulgarian language and their opinion if their religious believes, cultural identification etc. are respected was used. The results are processed by SPSS v. 14. A parametric test was used.

\section{RESULTS AND DISCUSSION}

Multiple ethnic, ethnographic and religious societies live at the territory of the Balkans. This, together with the economic backwardness of these communities, in comparison to the Western European nations,
MUSURLIEVA N, et al. forms a prerequisite for continuous conflicts on ethnic or religious base. At that background, Bulgaria looks like an "isle of peace" and there are numerous reason for that. Maybe the most important one is the prolonged (for centuries) cohabitation of various communities over the Bulgarian ethnic territory, which resulted in mutual cultural enrichment between these communities (which is most clearly seen in the language borrowings, the closeness of some folklore elements etc.). All of the above has contributed to the establishment of tolerance towards the "others". In the support of the above statement, the present study was performed and during its course, the hypothesis if the foreign students in general and dental medicine at Medical University Plovdiv feel the the tolerance to their different ethnic belonging by the fellow students and teachers was tested. At the question "For how long have you being in Bulgaria?", most of the respondents $-54 \%$ share that they have being in Bulgaria for more than three years (Figure 1).

Figure 1. Distribution of the answers to the question "For how long have you being in Bulgaria?"

As main reasons for their stay at the country are their studies, which is logical, considering the location where the interview took place. Three of the interviewed individuals state war as a may reason for their arrival (Figure 2).

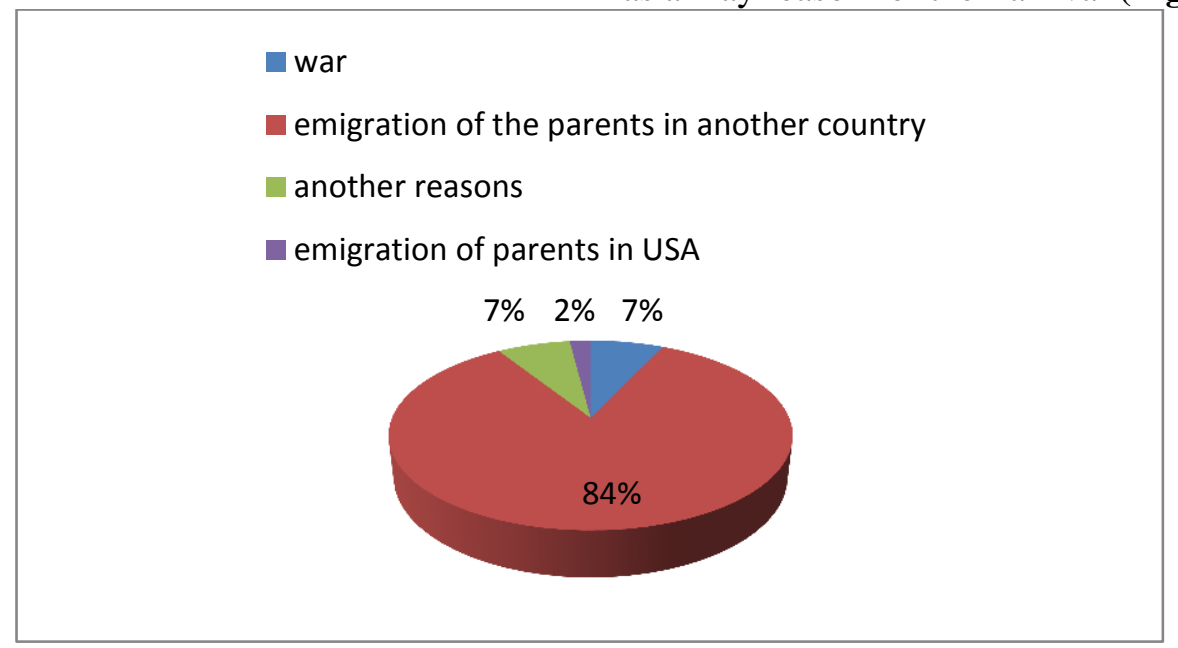

Figure 2. Distribution of the answers to the question "What are the reasons for your stay in Bulgaria?" 
Most $-70 \%$ of the interviewed know and speak Bulgarian language. Almost the same number of interviewed individuals are acquainted with the Bulgarian culture and customs (Figures 3, 4). This is a commendable result, considering the fact that the knowledge of the culture and the language of the hosting society is the major factor for the social integration of foreigners $(4,5)$.

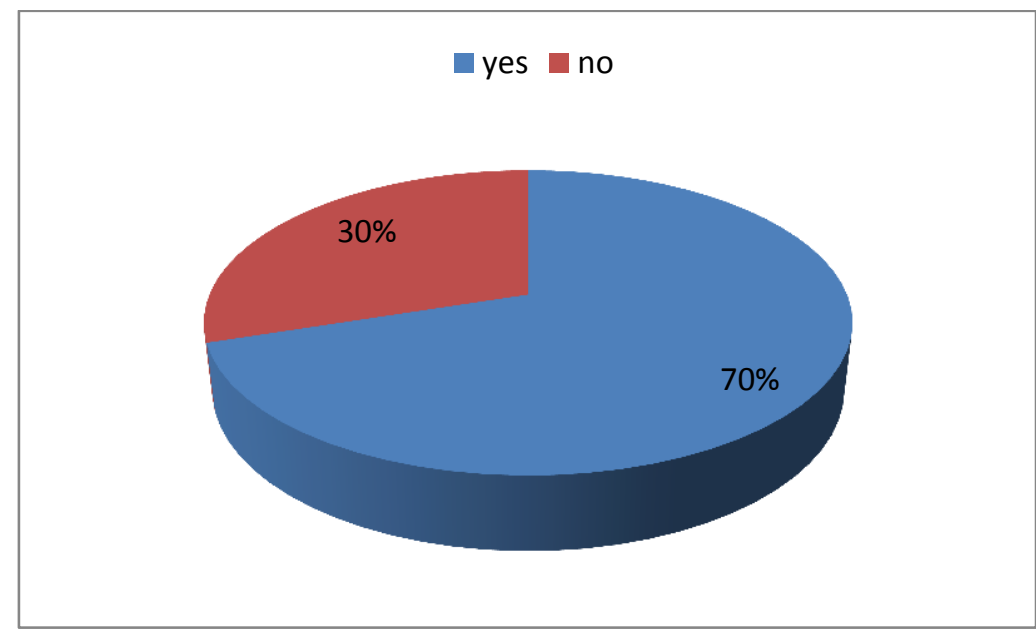

Figure 3. Distribution of the answers to the question "Do you speak Bulgarian language?"

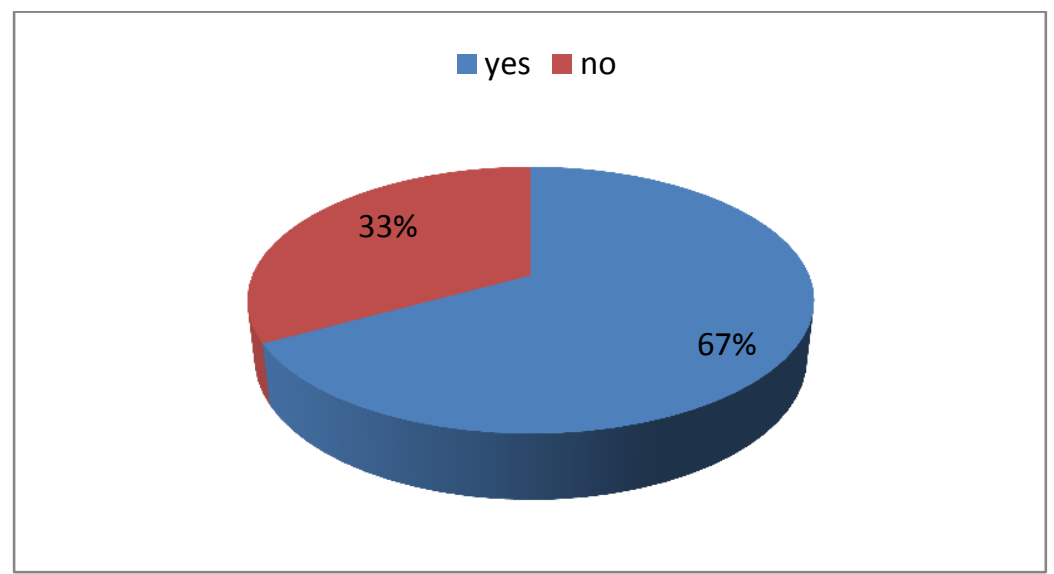

Figure 4. Distribution of the answers to the question "Do you know the Bulgarian traditions and culture?"

$67 \%$ of the students feel "welcomed" in Bulgaria and only eight share the opinion that they are "unwanted" foreigners. The relative share of those, who feel among the students community and the society "as Bulgarians" is relatively high (Figure 5). The result can be explained by the diversified social and academic life at the university - the existence of Foreign Students Association at the Medical University - Plovdiv, the organization of various events, like festivals, thematic evenings and balls.

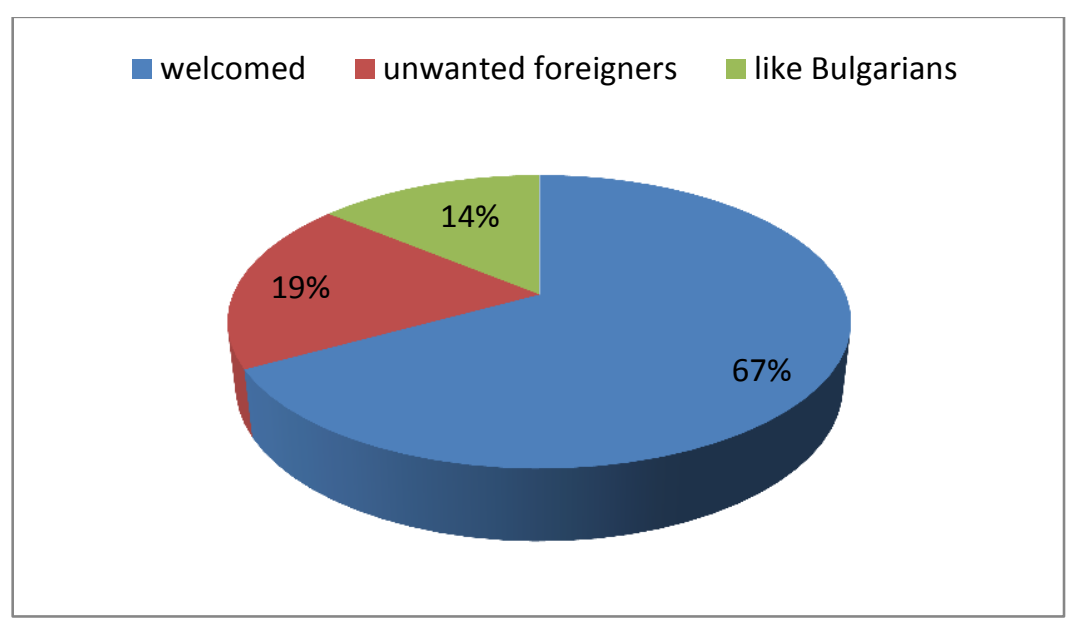

Figure 5. Distribution of the answers to the question "How do you feel in Bulgaria?" 
Limitations of the study: The present study is pilot and is covering a small number of interviewed individuals. It is required to extend the sample size in the future.

\section{CONCLUSION}

The study shows that the interviewed foreign students share the opinion that the academic and students community, as well as the society, in general, show tolerance and respect to their cultural identity.

The establishment of favourable, heterogeneous, multi-ethnic environment at the university is possible and its establishment should be supported by the encouragement of the application of positive, non-discriminative educational measures, organization of festivals, exhibitions, revealing the cultural ways of the various ethnicities.

\section{REFERENCES}

1. Sarosiek J, Dlugoledzka K et al. Tolerance of the students at the Medical University in
MUSURLIEVA N, et al. Bialystok for different race, language and religion. Arch Physiother Glob Res 18(1): 11-8, 2014.

2. Galishnikova E, Baklashova $\mathrm{T}$ et al. Formation of students tolerance in multicultural environment when teaching a foreign language. http://dx.doi.org/10.15405/epsbs.2016.07.7

3. Greenberg J, Simon L. Terror management and tolerance:does mortality salience always intensity negative reactions to others who threaten ones wolldview ? Journal of personality and social psychology 63(2):212-20, 1992.

4. Savchits NY, Ismailova SA et al. On the problem of ethnic tolerance formation in multicultural student environment. Man in India 97(3):285-296, 2017.

5. Safina R. The formation of students tolerance in a multiethnic school. International journal of environmental and science education 11(3):269-277, 2016. 